\title{
Analysis of Marketing Strategies in the Social Media: Facebook Case Analysis
}

\author{
Etienne Musonera \\ Mercer University-Atlanta \\ J. Michael Weber \\ Mercer University-Atlanta
}

\begin{abstract}
This paper uses a case analysis approach to address and analyze marketing strategies in the social media in general and Facebook in particular from its inception to now. We discuss how Facebook has strategically integrated its marketing activities to achieve superior results, and how it has managed to become and maintain its position as the premier social networking site around the world. We used Michael Porter's Five Forces to conduct industry analysis and we conducted a thorough evaluation. We selected, justified and recommended alternatives strategies that are consistent with Facebook mission, goals and objectives.
\end{abstract}

\section{INTRODUCTION}

Facebook is the world's largest social networking site for individuals, businesses, and groups. It has grown from a small social networking site geared for Harvard students to a brand that is recognizable and used around the globe. The current CEO, Mark Zuckerberg, launched The Facebook from his college dorm at Harvard in 2004 along with three of his friends. At the time, he never intended for it to become a global entity, or even catch on beyond Harvard's walls. Within one month of launching the website, the popularity increased exponentially. They soon had expanded the reach to other Boston area colleges, Ivy League schools, and Stanford. This was the beginning of their realization that there was vast potential to reach people all over who were looking for a way to feel connected with family, friends, and the world. Not two years after launching they would drop "The" from their name, and use the singular form "Facebook" which is recognized everywhere.

As Facebook grew, there was great uncertainty regarding its next steps. Many people were unsure whether Facebook was a business or just a social networking site. Potential investors wanted Facebook to focus on monetization in its early stages, but Facebook wanted to focus on growth and reaching people around the world. They were much more concerned with connecting the world, their original goal, then worrying about pleasing potential investors. So, they remained privately held, and funded mainly by venture capitalists for their first eight years. They worked on continuing to expand their use base, and offer Facebook in as many languages as possible. They also focused on adding new products such as timeline, news feed, games, groups, "Like" button, and numerous other new features which helped to grow the popularity further. This allowed them to grow their user base to almost one billion users before going public in 2012 . 
Once they turned public in 2012, they had to concern themselves with more of the business side of their company and create a vision for how to generate a return for their stakeholders and shareholders in particular, without sacrificing their vision of connecting the world. The obvious revenue generation opportunities stemmed from the magnitude of users on their site. Allowing advertisements was the easiest way to monetize their business, and they could do it without ruining the user experience by keeping ads to the sidebars or other noninterfering locations. It presented new opportunities for marketers to reach their target markets in a magnitude that wasn't possible beforehand. Marketers now had the opportunity to tailor advertisements based on user likes/dislikes, affiliations of groups, and even business to business interaction occurs on Facebook. In this analysis, we will look at the different challenges and opportunities that Facebook has it continues to find ways to monetize its business and connect the world.

\section{ENVIRONMENT ANALYIS}

\section{Economics Conditions \& Trends}

Since Facebook's launch in 2004, the company has remained strong with rapid growth around the world, despite economic downturns such as the stock market crash in 2008. Facebook has allowed for the connection of about 1.3 billion users since its initial startup as small niche for Harvard University students to connect and share ideas (Deloitte, 2015). Facebook has increased not only in popularity over the years gaining more users daily, but has also helped stimulate the economy worldwide.

\section{FIGURE 1}

\begin{tabular}{lrr} 
Macro-regional impact - Platform effects* & \multicolumn{1}{c}{$\begin{array}{c}\text { Econ. } \\
\text { Impact }(b n)\end{array}$} & $\begin{array}{r}\text { Jobs } \\
\left({ }^{\circ} 000\right)\end{array}$ \\
\hline $\begin{array}{l}\text { Region } \\
\text { North America }\end{array}$ & $\$ 9$ & 140 \\
\hline $\begin{array}{l}\text { Central and } \\
\text { South America }\end{array}$ & $\$ 1$ & 50 \\
\hline EMEA & $\$ 13$ & 270 \\
\hline APAC & $\$ 7$ & 200 \\
\hline Global total & $\$ 29$ & 660 \\
\hline
\end{tabular}

* Numbers may not sum due to rounding.

From the diagram above you can see how much of an impact Facebook has had on increasing the economy as well as the job market. Alone Facebook has found roughly 140 thousand people jobs in North America. Facebook's economic impact is also shown at roughly $\$ 29$ billion as they help promote the sale of goods and services for all markets that are willing to participate whether it is local Mom and Popshops or mega-corporations. Facebook's availability to promote and provide "free" marketing is what allows the success of these local shops. That in return allows the economy to thrive and become more stable and prosperous. However, Facebook itself has remains profitable by the various applications and platforms it is able to run on such as the constant flow of advertisements that are shown depending on the users appeared interests and wants. Facebook allows corporations to pay for time and space on their website as 
an additional way to increase awareness and popularity for the various target markets that are trying to attract.

\section{Cultural and Social Values \& Trends}

Facebook initially started as a way for college students to share ideas and interests and has positioned itself as a site where people can come together and connect with one another; They pride themselves in bringing the world closer together by living and working by 5 core values: Being bold, Focusing on impact, Moving fast, Being open, and Building social value (Facebook,2017). It makes sense that during an election year, the interactions on this social media platform grow at a rapid pace as discussions and information are constantly being updated with the latest polls and candidate information. It is because of the rapid availability of current information that voters constantly login to stay informed and up to date so that when time comes to cast your ballot voters feel confident in the choices that they are making. With that said there is also a large opportunity for the candidates to fill the viewer's screens with various advertisements promoting their visions and goals for the future. During the 2016 election, various analysts projected that Facebook was truly the winner of the election as $40 \%$ of digital advertising costs went to Facebook, equal to roughly 607 million dollars' worth of revenue (Bryan).

FIGURE 2

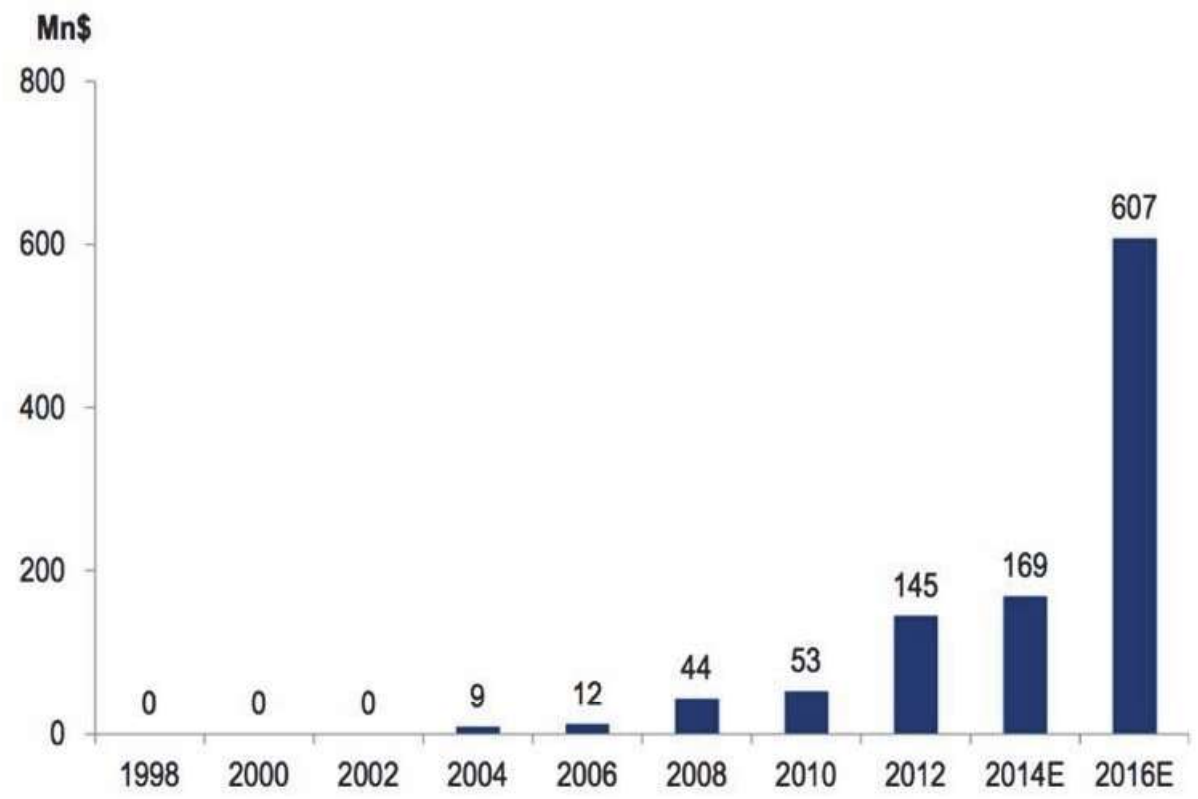

Bryan, Bob. "Facebook Could Be the Big Winner of the 2016 Presidential Election." Business Insider.

From these projections alone we can see the how strong the viewed perception is of Facebook's ability to reach billions of people at once and to allow the flow of thoughts and ideas to affect the views of everyone logging in as well as how they will make decisions. The overall consensus is that Facebook in today's cultural society provides a gateway for people to voice their opinions that may sway others to choose/ thinking differently as more facts and information is available for the average user.

\section{Political \& Legal Issues}

One of the biggest political issue that Facebook has been plagued with is the Russian interference in America's presidential election last year. It was alleged that Facebook sold $\$ 100,000$ worth of political 
Ads to fake accounts originating from Russia. These ads were used to manipulate the election. As a result, Facebook was under-fire by lawmakers accusing them of skewing the election (Guynn, 2017).

Facebook like any other social media platform has always been scrutinized for its lack of privacy, as many conspirators believe social media is used to monitor its users and gather information that these users may not want to share. For instance, this can be seen through the ads one user may come across versus another. Facebook gathers user's information such as what they Google on the internet or what stores websites they frequent the most in order to provide relevant ads for which they receive revenue to stream. Therefore if they successfully provide the right ad and the user purchases a product or service the company would continue to pay Facebook for its advertising and would in return keep Facebook profitable. Currently Facebook is facing legal issues from the European Court of Justice, as the justice system in Europe feels that Facebook is just a middleman for the US to gather information from the users of Facebook in their country (Farrell). This issue not only affects Facebook but any other company that provides a service and or product from the US to Europe and dates back years to when an agreement was made between the two countries. The Safe Harbor agreement was established in 1998 as a way for US companies to self-certify that any information that crossed over from Europe to the US stayed within the European Data Protection Standards when transferring personal data (Clark). With today's pressure from the EU Department of Justice Facebook will have to begin changing the ways that personal data is collected and will have to begin to abide by how Europe wishes to control how information is received and transferred.

\section{Summary of Environmental Opportunities \& Threats}

Facebook over the years has taken many opportunities, which has allowed them to stay in the forefront of social media. They also have the ability to adapt and create new ways for their users to remain attracted to their website and overall mission to keep people connected. With an estimated 2.07 billion active monthly users, Facebook has the opportunity to expand their advertising business reach (Facebook, 2017). As more of the population purchase mobile devices or gets more access to mobile devices, this provides Facebook with the opportunity to generate more revenue through mobile advertisement. Facebook has a multitude of opportunities to step into new markets and create new ways of people to stay connected. In a recent article, it stated that Facebook would soon compete with Uber, a fairly new corporation that provides easy and safe transportation (Rebecca Stewart, 2016). Facebook would be jump into their competitive market by connecting their already vast number of users to one another through similar events they are planning on attending and provide opportunities for carpools and/or setting up safe ways for a large group of users to get to the same destination such as a concert. Below is a diagram of what Facebook could potentially start offering its users when they RSVP to an event or when they create on event and share with friends. However, just as there are more people using Facebook, there are more sites or apps that are competing with Facebook for their users. This could potentially reduce the amount of revenue that the company could generate. 


\section{FIGURE 3}

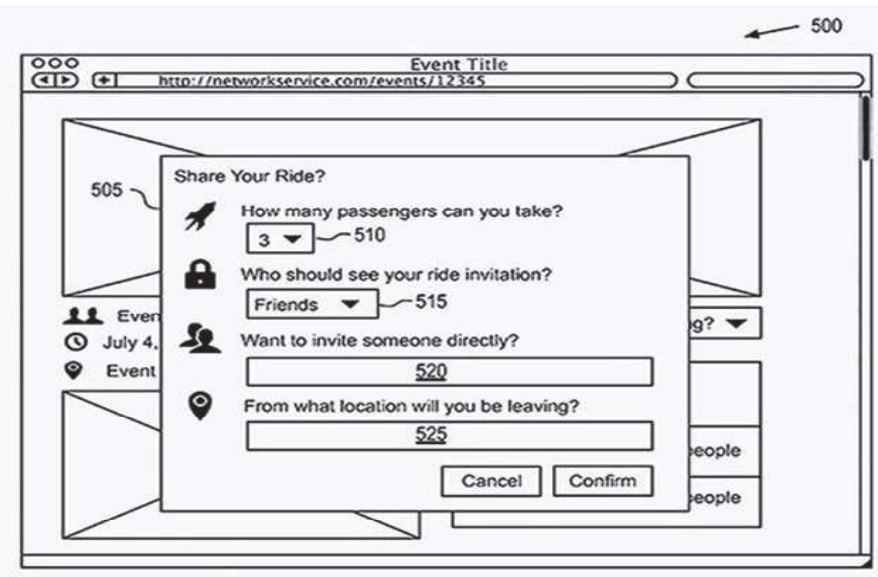

FIG. 5

O'Brien, Sara Ashley. "Facebook Is Eying Ridesharing." CNNMoney. Cable News Network, 28 Jan.

Although Facebook has a strong hold in the social media market and has a strong leading presence in today's society they are also faced with various threats. Being such a widespread platform that provides numerous outlets into the world and markets, Facebook lacks the specialized characteristic. That many of the smaller niche social media platforms have developed into, such as Instagram, Twitter and Pinterest. Instagram is solely for users to post/share pictures with their followers as well as catch up on other user's lives. Similarly, Twitter and Pinterest provide that one special place users can go to where they can see/find exactly what they are looking for at that moment in time. While, Facebook is a constant search and scroll through of a vast amount of information and external links that create a never-ending path. It is with this large amount of information that we believe smaller niche social media sites could be a large potential threat to Facebook as people in today's society are looking for a fast way to up to date with our fast pace environment. Facebook should identify their target customer or market and serve them better than the competition. From this, Facebook can build a more favorable reputation and gain more customers.

\section{INDUSTRY}

\section{Classification \& Definition of Industry}

In today's world technology and the internet have become integrated in practically everything we do. It is a constant struggle to stay up-to-date on events, news, and the lives of friends and families. Social media has created a simple way to stay informed of all aspects of social, personal, economic, business worlds and so many more. Facebook is among many companies which fall into the industry of media and specifically social media (Bloomberg). There are a wide range of users of social media platforms from businesses to individuals. Social media has created a one-stopshop to browse and share things such as news articles, current events, pictures, life events, shopping trends, sports news, and anything one could possibly imagine ever wanting to read about. Social media has changed the way we stay connected.

\section{Analysis of Existing Competitors}

The threat of existing competitors in the social media industry is strong because there are a multitude of other options available at the touch of a button. It is the job of the innovative teams at these respective social media companies to stay upto-date on the wants and needs of the consumer. It is also their job to create new ideas on how to share information in a seamless manner. Competitors catering to niche markets pose a threat to Facebook because they are more in tune with the specific area in which they are 
serving. Facebook has a wide variety of services offered throughout their application which can be an opportunity in that it gains a greater reach to all types of consumers, but also a threat in that smaller niche companies are able to capture the attention of smaller remote areas. Major competitors of Facebook include Twitter and YouTube. All of these competitors have a smaller following than Facebook, but cater to different wants of the consumer. Facebook holds the largest customer base with 1.55 billion of the 1.79 billion social network users worldwide; Twitter falls behind with 320 million users (Statistia). Facebook has kept ahead of the competition, and it will be necessary to maintain innovative strategies to remain there as new companies and technologies emerge. The emergence of new start-ups continue to eat away at market share that Facebook must retain. Therefore, attaining new users continues to be a challenge.

\section{Analysis of Potential New Entrants}

With the ever-changing wants and needs of consumers the threat of potential new entry into the social media industry is moderate. It is relatively inexpensive to create a new social media platform with an innovative way to capture users' attention. The cost comes into play in how to market the new social media platform, rather than creating it, and it is simple to gain acknowledgement given the current emphasize on advertisements being linked all over the web. A social media platform can be based off any specific idea or any wide range of ideas, which allows new companies to be created with ease. On the other hand, the current social media industry is saturated with developed and sustainable companies making new entry slightly more difficult. While consumers tend to be partial and repeat users to platforms such as Facebook, they are also willing to try to latest and greatest avenue of information sharing. The curiosity of consumers for new outlets of information sharing is where potential new entry gains power. There are barriers for new entrants that will be difficult to overcome. New entrants will find it difficult to provide the same quality and breadth of services that are competitive to the Facebook brand. Furthermore, it will be difficult to build loyalty of advertisers and active users which will weaken the threat of new entry against Facebook (O'Hara et.al, 2017).

\section{Analysis of Substitute Products}

A substitute performs a similar function by a different means (Porter, 1979). The threat of a substitute product reduces revenue and profit and can provide other challenges for Facebook. Other companies that feature mobile apps provide the strongest substitute to Facebook. For example, App.net is an alternative to signing into third party sites with your Facebook account. Common complaints from consumers are how Facebook gives data to third party users and manipulating its News Feed to display information that are not updates from your friends (Pullen, 2015) There are numerous social media platforms available for use today, making it simple for users to switch between their various options with little opportunity cost. The largest threat to Facebook for substitute products is other social media platforms catering to specific areas of interest. Another threat for substitute products would be new mobile applications because they could potentially draw attention away from Facebook users. As of December 31, 2015 Facebook had 1.44 billion mobile monthly active users (Facebook Newsroom). The ever-changing environment for the social media industry tasks each company with the goal of constantly adding new features to keep the current customer base and expand the customer base.

\section{Analysis of Suppliers}

Powerful suppliers have the ability to control the quality and quantity of the services being provided and are able to shift their costs to those purchasing the services for the customer (Porter, 1979). The threat of suppliers in the social media industry is weak because there are not many companies that have the capacity to support such social media giants as Facebook. Another aspect of supply to companies in the social media industry is knowledge and experience; these are required to maintain day-to-day information technology responsibilities. Suppliers can also include members of the innovative teams that create the new in-app features to expand the customer base and attract attention of current users to remain loyal. 


\section{Analysis of Buyers}

In the social media industry, buyer is a vague term. Buyers can be users of the social media platform or marketers looking to advertise on that platform. When considering buyers in terms of social media platform users, the threat of buyers is strong because these users have the opportunity to create profiles on an endless number of other social media platforms and spend their time there instead. Facebook has captured the attention of its current users and successfully maintained a market share of $45.4 \%$, followed by YouTube with $22.2 \%$ and Twitter with $4.8 \%$ (Statista). As Facebook is a continually growing company with the goal of continual customer base growth, it is expected that the threat of buyers in relation to social media users will remain evident, but not of major concern. When considering buys in terms of marketers, the threat of buyers is also strong because Facebook is among many offering contracts to advertise on their platform; the perception of the deal is in the marketers' mind though. The threat of buyers will always be evident, but Facebook has done a successful job at keeping ahead of the game.

\section{Summary of Industry Opportunities \& Threats}

Technology is ever changing, which presents Facebook will never-ending opportunities to better their product and expand their customer base. Major opportunities for Facebook would be expanding their customer base to untouched overseas markets, creating new interactive features within the original Facebook platform, and diversifying revenue sources. Constant expansion of customer base is a main goal of any social media platform; but there are certain untouched markets overseas due to government restrictions that Facebook has had difficulty gaining access to, such as China (Motley Fool). By gaining access to such markets, Facebook would exponentially expand their customer base, this would allow for new sources of revenue from other avenues of advertising and marketing. By creating new interactive features within the platform users will be more likely to spend a greater amount of time on the app or website.

In terms of opportunities, Facebook is the owner of the Oculus VR software which leaves the door open for additional revenue to be made in the forms of VR (Virtual Reality) games, and other apps that allow for a more connected Social Media interaction between users. Facebook also owns WhatsApp, which is not banned in China unlike Instagram and Facebook, because of this the company has become open to a very large market which it did not have access to in the past, the company could essentially monetize off of this market through the sale of its subscription services. Due to the number of users daily from Instagram, researchers have estimated that the value of this Facebook owned platform could grow to 10 Billion dollars in 2019 (Koetsir, 2017). Currently Facebook relies heavily on revenue from advertising and marketing within the platform (Strategic Management Insight). By finding new ways to create sources of revenue, Facebook will put itself in a position to not only be an even more financially stable company, but to expand their product base and product market as well

Threats to Facebook would be users start using other social media platforms more often than Facebook, government policy restrictions, and losing advertising revenue. There is a constant worry that users will stop using Facebook and start using another social media platform either instead of or more often than Facebook, it is the innovative team that is tasked with finding ways to avoid this tragedy and keep users engaged. Government policy restrictions could harm Facebook in that they could limit what kind of advertising can be placed within the platform, what kinds of in-app features can be created, and what markets Facebook is allowed to enter. Working with the legal team to create agreements and keep informed of all new corporate laws will allow Facebook to avoid encountering this issue. Losing advertising revenue would hurt Facebook because it is a major source of revenue, this can be avoided by diversifying revenue sources beyond advertising. In today's world, new opportunities and threats will constantly emerge causing Facebook and all other social media platforms to work tirelessly to stay ahead of the game.

A few years ago, Facebook experienced a decline in its revenue from its inability to display ads on desktops due to ad blocking software (Pratap, 2016). The continual development of ad blocking software could be a threat to the company's revenue particularly for desktop users. In addition. " Another major threat before the social media giant is the severe competition it faces from Google's AdWords as well as 
the social networking sites. Google still reaps the lion's share in online ads. Other social networking sites like Twitter are also making efforts to grow their share in online ad revenue (Pratap, 2016).

\section{Implication of Strategy Development}

Given the information that has been gathered regarding the Industry, there are some implications that can be drawn to devise strategies that will allow the company to expand its growth and increase its revenue. As we have read Facebook's sister company is expected to grow to $\$ 10$ Billion in 2019, however in order for the company to attain this goal it will need to ensure that its keeps its monthly user base steady and or grow it more. If it does not Snapchat will likely steal the Market as it has experienced more user activity than Instagram. Facebook should consider expanding the features of Instagram I.e. Adding more options to tinker with photos, added security for videos and even more interactive messages either through direct message or as a part of the comments on pictures.

It is recommended that Facebook capitalize on the Chinese market and monetize its "WhatsApp" application. This could be done through raising the price of subscription and researching new ways to reach this market in order to promote the application further. Facebook has lost revenue in the past from ad blocking software that does not allow ads to be displayed by desktop users. Due to this Facebook should create more incentive for users to access their websites through the mobile device. This can be done by adding features to the mobile application that the desktop does not offer. An example of this is Facebook Messenger, which is rumored to be expanding its mobile platform to offer more services, and has already began to allow mobile electronic payments.

\section{ORGANIZATION}

\section{Objectives \& Constraints}

Facebook was built to help people connect and share, and over the last decade, Facebook's tools have played a critical part in changing how people around the world communicate with one another. From its infancy, the organizational culture at Facebook was about open communication and nonhierarchical management. The offices at Facebook had always been open interactive spaces where the small team frequently met to troubleshoot and resolve issues. Preservation of the corporate culture was one of the top priorities for the company as it was growing (Purkayastha \& Qumer, 2011).To retain its culture, all its employees were put through a six-week Engineering Boot camp, where they not only learned about the company's product and processes, but also got exposure to Facebook's organizational culture and created lasting relationships with mentors. To ensure that the culture was instilled in its offices around the world, the organization made use of "landing teams." These were a group of experienced people from the head office at Palo Alto, who helped the new offices set up, hire and teach the recruits the Facebook culture.

According to Mark Zuckerberg (Facebook CEO), as of 2017 the company's mission statement has officially changed. Facebook's new mission and objective is to "Give people the power to build community and bring the world closer together." The CEO has reported that the world remains divided despite being more connected, although this connectedness has in part been aided by Social Media. The focus of Facebook moving forward will be to connect people to meaningful groups both online and offline. The CEO has expressed in his vision that a large amount of connection will take place offline and Facebook hopes to aide this offline connection through the Social Media platform.

Facebook faces the following constraints: retaining and increasing user engagement, reliance on advertising revenue, dependency on mobile operating systems, networks and even risks associated with new product development. Given these constraints the company should reevaluate its new objective.

\section{Bring Internet Access to the Other Two-Thirds of the World}

Zuckerberg described in his July 2014 WSJ article how roughly 2.7 billion people currently have Internet access. That sounds like a lot, but the majority of the world lacks connectivity. He knows 
Facebook's future growth is tied to increasing and sustainable investment in wireless infrastructure. The phrase "a rising tide lifts all boats" takes on significant implications not only for Facebook but also for its competitors.

\section{Make Facebook Mobile App Killer}

Flurry (the mobile ad and analytics firm Yahoo recently acquired for $\$ 200$ - \$300 million) says mobile users spend 17\% of their time on their phones in Facebook's app. This metric shows Facebook's mobile app is the most popular app on IOS and Android devices. Facebook's Q4 2015 Quarterly Financial Reporting slides show a consistent, steady climb in daily and monthly mobile users. Zuckerberg knows consumers live in a mobile, one-screen world. The only screen users care about is the one in front of them. Acquire Mobile Platforms, that Increase Short Term and Long Term Competitive Advantages. Prove Digital Marketing Results in Positive ROI (Tony Faustino, 2014)

\section{Financial Condition}

Facebook is currently in a very strong financial condition. In its second quarter of 2017, the company reported profits of nearly $\$ 4$ billion which is a $71 \%$ increase from its previous year where it reported profits of roughly $\$ 2$ billion (Chaykowski, 2017). These returns beat analyst predictions and have been attributed to growing demand for social networks, the company's ability to attract new users and also its mobile ads. Facebook users have increased a total of $17 \%$ and this includes both daily and monthly users. The company hopes that the volume of ads that they are able to show users will become a less important factor in the company's growth, which hints to the idea of new streams of income for Facebook. There appears to be only upward mobility from here, as Instagram is projected to grow to nearly $\$ 4$ Billion in revenue worldwide according to analyst and social media marketers. The company continues to have high hopes for its mobile data and virtual reality software which it hopes to expand and segue into additional markets. Facebook continues to improve its financial condition as it monetizes its business. They had great top line revenue growth YoY, up 44\%. Within that 44\% increase, they grew ad revenue by $57 \%$, which generates the vast majority of their revenue. They continue to invest dollars back into the business, Capex up 38\%, but have also had success growing their bottom line YoY, up 25\%.

\section{Management Philosophy}

Facebook stands for bringing users closer together and building a global community. Facebook ultimate philosophy is to develop a social infrastructure that give users the power to build a global and informed community, and to have the greatest positive impact on the world. Facebook tries to remind itself to focus on the following: Focus on Impact (find big problems to work on), Move Fast (and break things), Be Bold (take risks to stay ahead of the curve), Be Open (information sharing is crucial to better decision making), and Build Social Value (Forbes, Entrepreneurs).

\section{Organizational Structure}

Mark Zuckerberg - Founder, Chairman, \& CEO

Sheryl Sandberg - COO

David Wehner - CFO

Mike Schroepfer - Chief Technology Officer (CTO)

Chris Cox - Chief Product Officer (CPO)

Board Members: Mark Zuckerberg, Marc Andreessen, Susan Desmond -

Hellmann, Reed Hastings, Erskine Bowles, Peter Thiel, Sheryl Sandberg, \& Jan Koum

\section{Important Attributes to Organizational Structure}

Freedom to connect and share, ownership and control of information, free flow of information, fundamental equality, social value, open platforms and standards, fundamental service, common welfare, and transparent processes. (Jaypee Capville). Its organizational structure is designed to address creativity 
and innovation. The foremost features of Facebook's organizational structure are: Corporate FunctionBased Teams, Geographic Divisions, and Product-Based Divisions.

\section{Organizational Culture}

Facebook's open culture allows employees to work on problems that they care most about, and fosters a unique pride in problem solving. Facebook prefers to work in small teams, moving constantly to build new products, or reengineer and improve existing products. Lastly, they try to live by the creed "the journey is $1 \%$ finished", a constant reminder that their mission has just begun. (Cameron, K. S., \& Quinn, $R$. E.). Facebook Inc., which pushes employees to strive for improvement, labels itself as a hacker culture. Facebook's mission and vision statements emphasize making the world more connected which allows them develop and foster business resilience and competitiveness. Facebook's organizational culture can be characterized by: rewards creative problem solving and decision-making, boldness, openness, speed, and continuous improvement.

\section{MARKETING STRATEGY}

\section{Objectives}

Facebook's primary objective is to continue to appeal to individuals, business, and groups the world over. Facebook is known for its company motto "Bringing the World Closer Together" and in recent years has made profit by bringing users closer to buying merchant products. In terms of generating revenue, the social media network has focused on three basic priorities for ensuring that businesses continue to do business with the tech superpower: helping businesses expand their use of our mobile products, developing innovative ad products that help businesses get the most of their ad campaigns, and making our ads more relevant and effective through our targeting capabilities and outcome-based measurement. Facebook will continuously try to connect the world by offering products and resources that make people want to join their networking site. However, the company may face many constraints in emerging markets and underdeveloped nations, because people in these markets have a harder time accessing the internet. If you can't access the internet, then there is no tangible service Facebook can provide to these potential customers.

Since Facebook is free to join, it is easy to understand that their main objective is to sign up new individuals to their site. Facebook makes its money from companies paying for advertising, so they are constantly trying to grow their user base which leads to more money for advertisers. Also, since Facebook exists solely online, they don't have to worry about suppliers and distribution channels. They can control all of these aspects through their network of employed engineers, which again helps them remain solely focused on user growth. They don't have to devote time to other aspects of a traditional business. It is fairly easy for Facebook to interrelate their marketing strategies since they are really focused on user growth. They just need to keep developing compelling reasons for others to access their site, and continue to make it friendly for different cultures around the world. Although it may sound difficult to try and connect people around the world, they still benefit from not having to develop any real infrastructure around the world except for data centers to handle the large amount of data stored on Facebook servers. Facebook even realizes that its primary constraint, people around the world without internet access, is worth the investment to bring internet to these places. They have worked on providing internet access to people around the world, knowing the investment now, is worth the long run payoff from advertisements aimed at these emerging markets.

\section{Analysis of Sales, Profits, \& Market Share}

Facebook's sales and profits are directly tied to their market share, which really consists of their user base and that user base's average time spent on Facebook. Facebook's sales primarily consist of advertisement revenue generated, as well as some secondary revenue via games played through Facebook such as Farmville. Facebook isn't as concerned with profits to the same degree as more mature companies, as they understand that profit will inevitably grow as they continue to grow the user base. 
They are still in the growth phase, and there main concern is not turning all revenue into profit, but rather reinvesting that operating margin back into the business via capital investments and new product research and development.

Facebook recently announced full year (2015) earnings at the end of January. They continue to show impressive user growth, revenue growth, and even earnings growth. They realized a $44 \%$ increase in YoY (year over year) revenue, to $\$ 17+$ billion, which is impressive, and confirms that they are still very much in the growth stage. They also managed to increase their operating income from $\$ 5$ billion to $\$ 6.3$ billion, which was actually a drop in operating margin. This is still a positive absolute increase, and the drop in operating margin as a $\%$ of net revenue is indicative of them reinvesting those earnings back in to the business in a $\mathrm{n}$ attempt to continue their worldwide growth. In all, 2015, was a great year that saw increased revenue, via ad sales primarily, and also an increase in absolute operating income. Even though operating income was down as a \% of net revenue, as stated above, it is expected in a high growth business.

According to recent filings with the United States Securities and Exchange Commission (SEC) by Facebook, 97\% of its revenue was generated through third parties advertising on the social media in 2016 (SEC FORM 10-K, 2016). Though Google nearly double their profits Facebook still holds a majority of the market share at $61 \%$ according to some recent findings (Lardinois, 2015).

Most importantly, Facebook showed an impressive YoY daily user growth rate of $17 \%$. Facebook now averages over 1.04 billion users per day on its primary networking site. In addition to this impressive growth, they saw even more impressive growth in their mobile division. Increasing daily active users in mobile by $25 \%$ YoY, to 934 million active users per day. Lastly, they saw growth in both monthly active users of their traditional site as well as mobile users. Growing both user sets to 1.59 billion users, and 1.44 billion users, respectively. It is important to note that approximately $65 \%$ of their user base interacts daily with Facebook. It is easy to see why this user base is attractive to companies as a means of advertising, and why the continued growth in user base is important to Facebook.

\section{Analysis of Target Market (s)}

Facebook has a truly unique target market in that it is vast, and somewhat undefined, much in the same as Google. Although Google is not accommodating people in the same structure as Facebook. Facebook began as a company targeting a selection of students at specific universities, grew to accommodate all colleges, then high school students. After its first five years of targeting those specific student segments, it opened its door to the world, and the priority became connecting the entire world. In that respect, Facebook has made its target market anybody with internet access around the world. They are truly trying to connect the entire world and make it more open, which is clearly stated and embodied in their mission. Because Facebook's business success largely hinges on its ability to attract more and more consumers, for advertisers to target, they are continually developing new products to pull in all different market segments and provide everyone a reason to join Facebook. Beyond trying to attract new users and bring together all different segments of the market, they are trying to extract as much information from these users as possible. This is truly where there products become venues for targeting specific markets. Certain target markets may be more apt to play games, while others just want to share information between friends and family. Identifying what is important to these different groups and segregating them internally allows them to develop specific problems, as well as provide targeted advertising for their paying clients.

\section{Analysis of Marketing Mix Variables}

\section{Product:}

Facebook (social networking, games, messenger, video, mobile, places, etc.); Instagram; WhatsApp; Atlas (ad services and measurement platform); Oculus VR (virtual reality gaming). 


\section{Price:}

Facebook's service are free to its users aside from some revenue for credits in certain online games it offers. Its primary revenue is generated through advertisements. Its pricing towards advertising is tiered based on the needs of the ad in regards to text, information, photos, videos, placement, and the call to action. Also important in the tiered pricing is the expected reach of the advertisement. The advertisement pricing can be structured based on number of clicks, views, or people targeted over the ad duration. The estimated cost depending on all of these factors can cost the typical advertiser anywhere from 5 cents per click to $\$ 5$ per click on average.

\section{Place:}

Facebook and its offerings are open to anyone with internet access around the world (who aren't censored by their government). They are approaching 50 offices around the world, and offering Facebook in over 90 languages. Since they don't have a traditional brick and mortar structure, and exist solely online, their primary place decisions are centered on their workforce and data centers. These decisions directly impact users and their Facebook experience through processing times and unique features or languages around the world.

\section{Promotion:}

Facebook develops an integrated marketing communication plan primarily through the use of advertising and public relations. They outwardly advertise to potential users on the internet for their different services such as Facebook, Instagram, \& WhatsApp. These are mostly web banners, emails, or web ads that are targeted at consumer groups who would find some use in services offered by Facebook. Then they also will promote through the use of public relations. Mark Zuckerberg is a noted philanthropist, and every time he donates time, money, or resources to a cause, it helps promote the Facebook brand. They also generate buzz around the world via tech magazines, money and business magazines, and other articles or reports that explain their next moves. Lastly, they gain through public relations when radio DJ's or celebrities use their services to tell people what is going on or cover an event, such as via Instagram. As long as Facebook continues to please its 1.37 billion daily users companies will continue to want to advertise through Facebook with minimal marketing effort from the social media company to obtain these businesses (Facebook, 2015).

\section{People:}

Facebooks focus on people is an interesting dynamic, in that arguably the most important people aren't the consumers that are generating the revenue, but rather the free users whom the paying consumers (advertisers) are trying to target. So, Facebook obviously wants good working relationships with their paying consumers, but they also work extremely hard to create a better user experience that not only adds new users, but keeps people on their current platforms for longer periods of times

\section{Summary of Marketing Strategies}

Facebook has experienced great user growth from inception to date, and continues to put up impressive user growth year over year. This year Facebook celebrates thirteen years of success and is one of the few social media networks to stick around long enough to have a user base well over a billion people worldwide. This networking site has many marketing strengths that it both actively and passively uses to its advantage: Facebook proactively solicits its advertising services to companies through, ironically, advertisements on users' newsfeeds and it is easy to get started with step by step instructions right from the Home page on Facebook. This tech giant is constantly trying to improve its advertising services by promoting quality control, expanding mobile technologies, and basic customer and user satisfaction. Facebook is also strengthening its potential to monetize products like Instagram and WhatsApp. Facebook is able to market these potential new users to possible advertisers through their acquisition of Atlas, which helps show their advertising effectiveness to potential new advertising customers. Brief, Facebook strengths are user growth, new market development, new products for 
advertising development, and advanced analytics that help potential advertisers understand the success and failure of their marketing programs.

As of now, Facebook is still in a very high growth stage, but it does face some weaknesses with its markets and people in the longer term. For one, in the long run, it will be harder and harder to add new users. Saturation of any market increases as you increase the \% of market you have captured. This should be considerably far off though, as they are primarily generating revenue through the US, Canada, and Europe. They have a lot of monetization opportunities in Asia, South America, and the Middle East. Another weakness pertains to the people that Facebook must employ. As the operation becomes more global they must add more and more hardware to the system which requires huge capital investments for data centers around the world. There is always some inherent risk in these types of investment, especially with the pace that technology changes. These data centers could be out of date within only a few years, and then need to be upgraded. The other difficulty around its people is continuing to foster their culture across offices around the world, and retaining the talent needed to innovate new products internally. There is a decreasing marginal benefit in each engineer that must be added, in the fact that they become more technical and less innovative, which is how Facebook originally catapulted to the forefront of social networking.

\section{IMPLICATIONS OF PROBLEMS FOUND IN SITUATIONAL ANALYSIS}

\section{Statement of Primary Problem}

The primary problem that Facebook is currently facing is in the area of advertisements. Facebook generates the bulk of its revenue from advertisements and at present has over 5 million advertisers who utilize their services on a daily basis. As a company Facebook needs to keep its current advertising revenue growing, however this is a problem as Facebook admits that its average news feed is as full of ads as it can get (Ingram, 2016). The fact that Facebook has admitted to this issue is proof that the issue does indeed exist and that efforts will need to be made in order to remedy the matter if the company is to see continual growth in revenue from the Social Media site alone. The only alternative to this issue is for Facebook to begin introducing video advertisements. However, the company has not yet ventured into this lane as this mode of advertisements comes with its own set of problems; these include the fact that most people won't sit and watch pre-roll ads and these can be difficult to justify when they are only a few seconds long, in addition when inserting these into live streams one runs the risk of losing viewers (Ingram, 2016). There is an additional threat that will have an adverse effect on Facebook's growth. It is vital that Facebook must retain its younger active users and decrease their level of engagement with competitors. For example, in the United States, monthly active users between the ages of 12 and 17 years old will decline 3.4\% in 2017 (Ghosh, 2017). Snapchat is considered a strong competitor for young users. The social media platform has made tremendous strides in acquiring new teenage users since 2013. Currently in the United Kingdom, monthly active Facebook users between the ages of 18 and 24 years old will have declined by 3.1\% (Ghosh, 2017).

Facebook's primary problems will be continuing to grow its user base, increasing user utilization, and demonstrating tangible evidence of their value to advertisers. Facebook shows evidence of the importance in user growth by acquiring apps and firms that complement its core social networking site, as well as focus on products or areas that expand the attractiveness of their products. This indicates they are keenly aware of the importance in user growth and realize a potential problem from stagnant growth. They also know they must demonstrate value to advertisers, or risk losing advertisers to other social media sites such as Twitter, LinkedIn, and Snap Chat. Their acquisition and development of Atlas is an indicator they realized they had a potential problem in demonstrating the value they are bringing to advertisers.

Facebook's shareholders and stakeholders recognize the importance of both of these potential long term problems, and will begin to trade the stock accordingly or invite activist investors if they cannot solve these potential problems themselves. The brand is far too valuable to languish, so as soon as growth 
begins to plateau, investors will start to make question leadership and valuation. This could affect future debt or equity offerings needed to fund future development.

\section{Statement of Secondary Problem (s)}

One of the secondary issue facing Facebook is the sheer number of alternative options for advertisers on the internet, and some may offer more targeted ways for advertisers to reach their specific market segments. There are a number of competitor options that advertisers can utilize, even if they don't have the same magnitude as Facebook. These options include Twitter, but also nontraditional social media like LinkedIn, Google, Pinterest, iHeart, Pandora, YouTube, etc.

Another secondary problem is the past few months Facebook has been in legal controversy with Europe for the way that they process personal data as well as how Facebook tracks users and non-users of their site. Back in October the European Justice System nullified a 15 year long agreement between the US and Europe that allowed US companies to self-certify that they were staying within the European Data Standards. This came about after Europe noticed that Facebook was not abiding by their normal set of standards and that Facebook even had the ability to track non-users through cookies they were able to place on the non-users computer after they visited a public Facebook site. This issue brings to light the unawareness and lack of legal control Facebook has set in their privacy policy, which makes legal for them to obtain all of this information.

The alternative options for advertisers will help suppress advertising rates on Facebook, because there are viable alternatives to Facebook. Ultimately, as long as these other venues exist, it will help keep some ceiling on the prices that Facebook can charge its customers to advertise on their network. This becomes an earnings issue as the company matures, and investors might want to see other ways to monetize the business.

Facebook will now be under strict scrutiny for the way that personal data is captured as well as monitored via their various media platforms. A new agreement has been settled on called the EU-US Privacy Shield, which will force the way Facebook and many other companies collecting personal data from Europe to operate. The Privacy Shield will enforce stronger monitoring from the US Department of Commerce and Federal Trade Commission as well as a more interactive role from the European Data Protection Authorities. These stronger regulations will definitely impact the amount of data Facebook will now be able to receive compared to what they once had. As a result of this controversy. Facebook's users may now be more reluctant to freely search the web like they once had, now knowing that Facebook is able to follow their internet "footprint" past their Facebook profile.

\section{RECOMMENDATIONS AND STRATEGIC ALTERNATIVES}

\section{Strategic Alternative 1}

Facebook will need to add users and increase utilization, both in time spent and daily interactions with the Facebook suite of products. This can be achieved through continued focus on products that create new benefits for users, as well as acquisitions of products that target unique audiences outside of Facebook's current user base. They will also continue to add users as their presence increases around the world, particularly Africa, South America, Asia, and the Middle East.

Benefits of achieving user growth through increased market presence around the globe is that it is organic growth, and the lowest growth on a cost per user basis. It also helps them to achieve their organization's mission. The benefits of achieving user growth through new products and acquisitions is that it drives user growth up, and hopefully increases utilization of services both in length of time spent and frequency of user interaction. Also, some acquisitions take place quietly, and siphon off customers who intentionally don't want Facebook profiles, but now are unknowingly part of the brand through an acquired product.

The costs associated with global market growth are part of Facebook's ordinary business costs, and mainly involve FTE, marketing, and capital costs. They will need to invest in more data centers, capital intensive, to accommodate global user growth. However, these are costs that Facebook is planning to 
encounter, and is actual good expense in their eyes. The costs of new products mainly comes in the form of increased salary expense related to product engineers and coders. They will have internal analysis as to whether the product growth is worth the investment. The largest expense from this strategic development comes in the form of acquisitions, particularly because Tech valuations are extremely high right now. Startup tech companies are selling into the billions, sometimes based on extremely aggressive future growth. This is increasing costs to Facebook for these acquisitions.

\section{Strategic Alternative 2}

Facebook could also chose to focus more on revenue generation by demonstrating value that it is bringing to advertisers. This is a strategic alternative that has a readily available approach through continued expansion of their Atlas product. The benefits of focusing on their current revenue generation helps Facebook ensure that they are maximizing their monetization of current products generating revenue. It also allows them to build blueprints and understand success or failures as they continue to introduce new products. The direct benefits of continuing to expand Atlas, which shows the value of Facebook as an advertising platform, will show in increased revenues in the US, Canada, and Europe. However, it has the potential to pay much bigger dividends as Facebook expands to more untapped markets. Even though they are growing user base in other parts of the world, they have not begun to monetize those markets. It will be easier to cross cultural barriers and monetize the business when they can show potential advertisers the precise value they can expect to gain from advertising with Facebook.

The costs associated with this alternative will be primarily associated with the engineering and implementation costs of continuing to improve the Atlas product. Secondary costs will be the FTE's needed around the globe to promote Facebook and make connections with local advertisers around the world. Another cost which is harder to measure, is that this strategic alternative doesn't necessarily directly promote user growth and connecting the world, which is Facebook's mission.

\section{Strategic Alternative 3}

Facebook needs to look for alternative revenue streams, as they are extremely dependent on advertising revenue in their current business model. This may be achieved through acquisition of companies or products outside of their social media portfolio. The benefits of finding alternative revenue streams is they become less dependent on advertising revenue as their sole form of success. Advertising revenue could be susceptible to downturns and also the large number of options that are available to reach consumers. So, having other areas of revenue growth are extremely important. Companies like Oculus, acquired by Facebook, will provide alternative revenue streams through the purchase of the gear, games, and accessories. Other opportunities that may present themselves as alternatives, would also be targets for acquisition by Facebook. The largest costs are associated with the acquisition costs of these potential companies or products. Especially those in the tech sector, as large sums of cash are being generated in Silicon Valley to pay for companies without proven revenue streams or business models. So, acquisition costs are extremely high right now, and don't guarantee any type of short or long term success.

Facebook will predominantly focus on strategic alternative 3 by continuing to grow the overall user base, as well as utilization of all services. Components of strategic alternative 3 will also be utilized as opportunities present themselves. Strategic alternative 1 allows them to continue focusing on the objective that has the greatest long term potential return on investment, and also fits their mission. Ultimately, revenue growth only continues with an expanded user base, and a user base that utilizes the services at an expanding rate. Lastly, this strategy best fits their mission to make the world more open and keep people connected.

\section{Implications for Strategic Development}

Facebook's strategic development for the foreseeable future is to basically keep focusing on their core business and products that attach on easily. They don't need to do anything revolutionary at this moment. They need to focus on continuing in their current growth phase. It appears that they are aware of this, and have indicated during analyst earnings calls that their intent is to continue down their current path. They 
will continue to focus primarily on user growth, and also length of time the average user spends on Facebook and its family of products. They will also work on ways to monetize their current suite of products (Instagram, WhatsApp, Mobile) which are generating either no revenue or very little. The benefit of trying to monetize those products for Facebook is that they can leverage their own user base for advertisement, and each of those Apps were in very high growth phases when Facebook acquired. User growth and ad revenue growth will also shift from primarily North American and European primary objectives to include further reaches in the world, such as Asia, Middle East, and South America. Eventually these user growth and ad revenue goals will shift to Africa and further reaches like Eastern Europe. A third implication for strategic development will be the continued development of its business relations with Advertisers and expanded capabilities of Atlas. As Facebook continues to refine ways that it can allow advertisers to reach their market, they will be able to command even more premium dollars (higher \$ per click), but will still maintain flexibility to allow small businesses to blanket markets at lower $\$$ per click. They are creating a full spectrum of ad pricing that should help them maximize their revenue potential, at the same time they are growing their core business. The user growth also plays into the relationships with advertisers, in that if they continue to add users, then advertisers can't ignore them. Facebook simply becomes too valuable of an advertising pipeline for companies to ignore because of their sheer reach.

\section{SUMMARY AND CONCLUSION}

Facebook is a multi-billion dollar company which generates a vast majority of its profits through advertising to user on behalf of third party businesses. This case presented several analysis looking at the environment that affects the prosperity of companies like Facebook as well as individuals. An in depth look at the tech and advertising industry as a whole was evaluated to determine the strengths of the competitors and the willingness of the buyers to engage in profitable relations. Furthermore, a microscopic analysis of Facebook as an individual company revealed how it functions amongst the cutthroat competition and it successfully manages to solicit its advertising services to companies needing to reach consumers. Several problems were encountered such as the overwhelming majority of its revenue generated through a single means, how Facebook will retain its users, and problems restricting unwanted access to servers and profiles. This year Facebook celebrates its thirteenth birthday, lucky number thirteen; is this the year another company rises to the top or will Facebook mature and remain the leading company in the online advertising business.

Facebook has managed to become and maintain their position as the premier social networking site around the world. They have had a unique beginning as a company as they were not concerned with being a viable business at first, but rather concerned with creating their vision of how best to connect the world. It wasn't until their user growth exploded that they began to focus on monetizing their social networking site, primarily through the use of advertisers on Facebook. As they continue to grow their user base and provide useful reach and capture data to advertisers, they will continue to increase both top and bottom line for the foreseeable future. They have considerable growth opportunities around the world, and have not yet monetized Facebook in many countries outside of the US, Canada, and EU. In addition to monetizing Facebook, they are still creating ways to better monetize the mobile Facebook app, Instagram, WhatsApp, and other Facebook owned products or Apps. As a secondary strategy they have also begun to acquire firms not necessarily aligned with social networking such as Oculus, in an attempt to generate

revenue outside of advertising. Led by Mark Zuckerberg and team, Facebook will be expected to continue its current growth trends, and continue to deliver earnings reflecting its growth. Barring potential privacy issues which could impact the business from regulatory angles, as well as diminished brand perception, the long term goal seems apparent for Facebook: grow users and prove value to advertisers. 


\section{REFERENCES}

Ashkenas, R., Ulrich, D., Jick, T., \& Kerr, S. (2015). The boundaryless organization: Breaking the chains of organizational structure. John Wiley \& Sons.

Bernroider, E. (2002). Factors in SWOT Analysis Applied to Micro, Small-to-Medium, and Large Software Enterprises: an Austrian Study. European Management Journal, 20(5), 562-573.

Bryan, Bob (2016). Facebook Could Be the Big Winner of the 2016 Presidential Election. Business Insider Inc. Business Insider, 06 February.

Chaykowski, K. (2017). Facebook Shares Rise On Fourth Quarter Revenue, Earnings That Blow Away Estimates. https://www.forbes.com/sites/kathleenchaykowski/2017/02/01/

Christopher, Matthews (2014). More Than 11 Million Young People Have Fled Facebook Since 2011. https://business.time.com

Clark, Kelli. (2016). The EU Safe Harbor Agreement Is Dead, Here's What To Do About It. Forbes Magazine.

Constine, J. (2017). Facebook changes mission statement to 'bring the world closer together. https://techcrunch.com/2017/06/22/bring-the-world-closer-together/

Deloitte. "Facebook's Global Economic Impact." (2015): n. pag. 2015. Web. 6 Feb. 2016.

Facebook (2016). Company Info. Retrieved from the Facebook website http://www.newsroom.fb.com/company-info

Facebook (2016). Ads Guide. Retrieved from the Facebook website http://www.facebok.com/business/ads-guide

Facebook (2016). How Does Facebook Make Its Money? In Business Management Degrees. Retrieved from http://www.business-managementdegree.net/facebook/

Facebook (2016). Company Info | Facebook Newsroom. N.p., n.d. Web. 31 Jan.

Facebook (2016). FY 2015 4th Quarter Earnings Release \& Earnings Transcript. Retrieved from the Facebook website http://www.investor.fb.com/results

Facebook Inc. (2016). SEC Form 10-K

Facebook. (2017). Facebook's 5 Core Values. https://www.facebook.com/media/set/?set=a.1655178611435493.1073741828.1633466236940064.

"FB: NASDAQ GS Stock Quote (2016). Bloomberg.com. Bloomberg, n. d. Web. 31 Jan.

Farrell, H. and Newman, A. (2016). Facebook Is at the Center of a Huge Privacy Controversy. For Once, It Isn't Facebook's Fault. Washington Post. The Washington Post, 25 Sept. 2015. Web. 06 Feb. 2016.

Faustino, Tony (2014). 5 Objectives Mark Zuckerberg Tracks for Facebook's Domination. https://www.linkedin.com/.../20140817211054-31240456-5-objectives-mark-zuckerb

Gallaugher, J. M. (2008). Facebook Case. Retrieved November 7, 2012, from Gallaugher.com: http://www.gallaugher.com/Facebook\%20Case.pdf

Ghosh, S. (2017). Facebook Really is losing teen users to Instagram and Snapchat. http://www.businessinsider.com/facebook-losing-teen-users-faster-to-Instagram-and-snapchat

Guynn, Jessica (2017). Facebook political ads are coming out of the shadows - why you should care? USA TODAY.

Guynn, J. (2017). Facebook Political ads are coming out of the shadows - why you should care. https://www.usatoday.com/story/tech/news/2017/09/28/facebook-russia-politicals-ads-markzuckerberg/698015001/

How does the online advertising industry work? http://smallbusiness.chron.com/online-advertisingindustry-work-37486.html

How Facebook is Putting Serious Pressure on Marketing Data Vendors (n.d). https://www.huffingtonpost.com/entry/how-facebook-is-putting-serious-pressure-onmarketing_us 595c07b9e40f078efd98cf7 
Jackson, S. E., Joshi, A., \& Erhardt, N. L. (2003). Recent research on team and organizational diversity: SWOT analysis and implications. Journal of Management, 29(6), 801-830.

Jurevicius, O. (2013). SWOT Analysis of Facebook. https://www.strategicmanagementinsight.com/swotanalyses/facebook-swot-analysis.html

Kinahan, J.J. (2017). Facebook (FB) Earnings Preview: The Social Media Giant Reports Tomorrow. https://tickertape.tdameritrade.com/trading/2017/07/facebook-fb-earnings-q2-2017-94890

K. S., \& Quinn, R. E. (2005). Diagnosing and changing organizational culture: Based on the competing values framework, Jossey-Bass.

Koetsier, J. (2017). Citi: Snapchat Revenue To Hit \$3B In 2019, Instagram at \$10B. https://www.forbes.com/sites/johnkoetsier/2017/08/08/

Lardinois, F. (2015). Facebook Continues To Dominate Social Logins, Expands Lead To 61\% Market Share. https://techcrunch.com/2015/01/27/facebook-dominates-social-logins/

Leigh, D., \& Pershing, A. J. (2006). SWOT analysis. The Handbook of Human Performance Technology, 1089-1108

Lombardo, J. (2017). Facebook Inc.'s Organizational Structure Analysis. http://panmore.com/facebookinc-organizational-structure-analysis

Oberoi, A (2013). The History of Online Advertising. Retrieved from https://www.adpushup.com/blog/the-history-of-online-advertising.

O'Brien, Sara Ashley (2016). Facebook Is Eying Ridesharing. CNN Money. Cable News Network, 28 Jan. 2016. Web. 06 February

O'Hara N.N, Nophale, L.E., O'Hara, L.M., Marra, C.A., Spiegel, J.M.. (2017). Tuberculosis testing for healthcare workers in South Africa: A health service. Analysis using Porter's Five Forces Framework. International Journal of Healthcare Management (10): 49-56

Porter, M.E. (1979). How competitive forces shape strategy. Harvard Bus Review, 57(2):137-156

Pullen, J.P. (2015). The 7 Best Facebook Alternatives You Didn't Know About. http://time.com/3722915/best-social-networks/

Pratap, A. (2017). A SWOT analysis of Facebook. https://www.cheshnotes.com/facebook-swot-analysis$\underline{2016 /}$

Reynolds, Simon (2013). Making Mark Zuckerberg's Business Philosophy Work, High Performance Coach for CEOs and Entrepreneurs, Forbes Entrepreneurs, Nov. 28.

Young, J. (2017). Five-Forces-Analysis-Recommendations-Porter's-Model http://panamore.com/facebook-incl

Withey, M. J., \& Gellatly, I. R. (2015). Organizational Structure, Situation Strength and Employee Commitment: Test of a Process Model. Academy of Management Proceedings (Vol. 2015, No. 1, p. 14587). Academy of $M$ 